\title{
Supratentorial hemispheric ependymomas: an analysis of 109 adults for survival and prognostic factors
}

\author{
Todd Hollon, MD, ${ }^{1}$ Vincent Nguyen, MD, ${ }^{3}$ Brandon W. Smith, MD, MS, ${ }^{1}$ Spencer Lewis, BS, ${ }^{1}$ \\ Larry Junck, MD, ${ }^{2}$ and Daniel A. Orringer, MD'
}

Departments of ${ }^{1}$ Neurosurgery and ${ }^{2}$ Neurology, University of Michigan, Ann Arbor, Michigan; and ${ }^{3}$ Temple University Medical
School, Philadelphia, Pennsylvania

OBJECTIVE Survival rates and prognostic factors for supratentorial hemispheric ependymomas have not been determined. The authors therefore designed a retrospective study to determine progression-free survival (PFS), overall survival (OS), and prognostic factors for hemispheric ependymomas.

METHODS The study population consisted of 8 patients from our institution and 101 patients from the literature with dis-
aggregated survival information $(n=109)$. Patient age, sex, tumor side, tumor location, extent of resection (EOR), tumor
grade, postoperative chemotherapy, radiation, time to recurrence, and survival were recorded. Kaplan-Meier survival
analyses and Cox proportional hazard models were completed to determine survival rates and prognostic factors.
RESULTS Anaplastic histology/WHO Grade III tumors were identified in $62 \%$ of cases and correlated with older age.
Three-, 5-, and 10 -year PFS rates were $57 \%, 51 \%$, and $42 \%$, respectively. Three-, 5 -, and 10 -year OS rates were $77 \%$,
$71 \%$, and $58 \%$, respectively. EOR and tumor grade were identified on both Kaplan-Meier log-rank testing and univariate
Cox proportional hazard models as prognostic for PFS and OS. Both EOR and tumor grade remained prognostic on
multivariate analysis. Subtotal resection (STR) predicted a worse PFS (hazard ratio [HR] $4.764, p=0.001$ ) and OS (HR
$4.216, p=0.008$ ). Subgroup survival analysis of patients with STR demonstrated a 5 - and 10 -year OS of $28 \%$ and $0 \%$,
respectively. WHO Grade III tumors also had worse PFS (HR 10.2, $p=0.004$ ) and OS (HR 9.1, $p=0.035$ ). Patients with
WHO Grade III tumors demonstrated 5 - and 10 -year OS of $61 \%$ and $46 \%$, respectively. Postoperative radiation was not
prognostic for PFS or OS.

CONCLUSIONS A high incidence of anaplastic histology was found in hemispheric ependymomas and was associated with older age. EOR and tumor grade were prognostic factors for PFS and OS on multivariate analysis. STR or WHO Grade III pathology, or both, predicted worse overall prognosis in patients with hemispheric ependymoma.

http://thejns.org/doi/abs/10.3171/2015.7.JNS151187

KEY WORDS brain tumor; ependymoma; glioma; prognosis; survival; oncology

I NTRACRANIAL ependymomas are the third most common glioma in adults, behind astrocytomas and oligodendrogliomas. Ependymomas constitute 3\% of primary CNS tumors and $6.7 \%$ of gliomas diagnosed each year in the US. ${ }^{31,32}$ Safe maximal resection remains the mainstay of treatment. Radiation and chemotherapy may be provided as adjuvant treatments, especially in the setting of subtotal resection (STR). Reported 5-year overall survival (OS) rates for adults with intracranial ependymoma range widely from $35 \%$ to $90 \% .^{9,19,21,47,54}$ Controversy exists regarding important prognostic factors for progression-free survival (PFS) and OS..$^{1,37,57}$ Reported prognostic factors include age, Karnofsky performance status, tumor location, tumor grade, extent of resection (EOR), and postoperative radiation. ${ }^{8,9,19-22,46-48,54}$

Evidence supports the idea that supratentorial ependymomas have a worse prognosis than infratentorial tumors do in adults. 9,19,20,23,38,45,46 Additional data indicate that patients with hemispheric ependymomas have decreased PFS and OS compared with tumors occurring in the third or lateral ventricles. ${ }^{9,45}$ Although often considered an intraventricular tumor, more than half of supratentorial ep-

ABBREVIATIONS EOR = extent of resection; GTR = gross total resection; OS = overall survival; PFS = progression-free survival; STR = subtotal resection.

SUBMITTED May 21, 2015. ACCEPTED July 27, 2015.

INCLUDE WHEN CITING Published online January 8, 2016; DOI: 10.3171/2015.7.JNS151187. 
endymomas occur within the cerebral hemispheres. ${ }^{9,22,39,57}$ Their hemispheric location likens ependymomas to the other primary intraaxial gliomas. Survival rates and prognostic factors for the most common hemispheric gliomas, astrocytoma and oligodendroglioma, have been well investigated in several clinical studies..$^{10,16,43,50}$

A large clinical investigation of hemispheric ependymomas is lacking, with the current literature consisting of case reports and small case series. Because these tumors potentially carry the worst prognosis of all ependymomas, accurate survival rates and prognostic factors would provide essential clinical information. We reviewed and statistically analyzed our institutional case series in conjunction with cases reported in the literature to more accurately determine the survival rates and prognostic factors of hemispheric ependymomas.

\section{Methods}

\section{Patient Population and Article Selection}

Our patient population consisted of 2 groups. The first group was all patients 18 years of age or older diagnosed with supratentorial hemispheric ependymomas at the University of Michigan from 1981 to 2014. Approval from the University of Michigan Institutional Review Board was obtained before medical records were accessed. A total of 11 patients were identified. One patient was excluded because tissue diagnosis demonstrated ependymoblastoma, one patient was excluded due to myxopapillary histology, and the third was excluded due to lack of survival data.

The second patient population consisted of all adults ( $\geq 18$ years of age) with supratentorial hemispheric ependymoma reported in the literature with disaggregated clinical information. This was defined as any patient reported in the literature with individually listed patient characteristics (e.g., age, sex, tumor side and location, treatment) and survival times (PFS and OS). Statistical data or calculated values from the literature were not included for analysis. The English-language literature was reviewed for clinical articles pertaining to supratentorial hemispheric ependymomas. PubMed searches for the terms "hemispheric ependymoma," "ectopic ependymoma," "cortical ependymoma," "extraventricular ependymoma," and "lobar ependymoma," combined with a "human species" filter, was performed. We chose to use the term "hemispheric" to emphasize that these tumors are intraaxial parenchymal tumors located within the cerebral hemispheres. After review of study abstracts resulting from the search, a total of 53 studies performed between 1985 and 2014 were deemed appropriate for article review. Each article was individually reviewed for disaggregated patient data. Studies with only aggregated patient data were excluded. Patients were excluded if they were less than 18 years of age, had no overall survival data available, or had an intraventricular tumor location. Ultimately, clinical data were obtained from 27 of 53 articles, and 101 patients from the literature were identified. ${ }^{3,4-7,11,13-15,17,18,24-26,27-29,34,35,40-42,44,49,52,53,58} \mathrm{Ar}$ ticle authors were not contacted for additional data. A total of 109 patients from both study populations were included in our investigation, and 77 patients had complete clinical information as described below.

\section{Data Collection}

The following patient data were collected either from chart review or extracted from case reports and case series obtained in the literature search outlined above: age at diagnosis; sex; tumor side and location; extent of tumor resection (dichotomized to subtotal resection [STR] vs gross-total resection [GTR]); WHO tumor grade, histology, or both; postoperative radiation; postoperative chemotherapy; total follow-up time; time to recurrence; PFS; and OS. All patients underwent craniotomy for tumor resection. No patient had a biopsy only. Gross-total resection was defined as no evidence of enhancement on T1weighted postgadolinium MRI for our institutional series. Subjects with absent or unknown data for any of the above clinical items were excluded from statistical analyses for that item to avoid inaccuracy or estimation. The number of patients included for each statistical analysis is indicated in the appropriate tables.

\section{Statistical Analysis}

Age, PFS, and OS were analyzed as continuous variables. Age $>40$ or $\leq 40$ years, sex, tumor side, tumor location, tumor grade, EOR, postoperative radiation, and chemotherapy were analyzed as categorical variables. Two survival outcomes were assessed: PFS and OS. PFS was defined as time from resection to radiological evidence of recurrence for our institutional series or PFS time interval reported in the article. OS was defined as the time from tissue diagnosis to death or OS time interval reported in the article. Eight patients in the series did not have data regarding recurrence or PFS. These patients were excluded from the statistical analysis of PFS. Kaplan-Meier survival function curves were constructed both for PFS and OS, using each prognostic factor (age, sex, tumor side, tumor location, EOR, tumor grade, postoperative chemotherapy, and postoperative radiation). The log-rank test was used to calculate $\mathrm{p}$ values for statistical significance between survival curves. Univariate Cox proportional hazard analysis was used to evaluate variables as prognostic factors for PFS and OS. Multivariate analysis was completed and included age, sex, tumor side, tumor location, EOR, tumor grade, postoperative chemotherapy, and postoperative radiation. Statistical significance was determined by ANOVA for continuous variables. The Pearson chi-square test or Fisher exact test (expected count $<5$ ) was used for categorical variables. Statistical significance was defined as a $p$ value $<0.05$. All $\mathrm{p}$ values were calculated using a 2-tailed test. Variance about the mean was reported as $95 \%$ confidence interval (CI) or standard deviation. All statistical analyses were completed using SPSS software (version 22, IBM Corp.).

\section{Results \\ Patient Characteristics}

A summary of baseline patient characteristics for all patients is presented in Table 1. Mean follow-up time was $5.29 \pm 5.87$ years with a range of 0.8 to 28.0 years. Mean age was $40.0 \pm 16.3$ years with a range of 18 to 74 years. Males and females were approximately equally affected. The 2 most common tumor locations were the frontal (33\%) and parietal lobes (22\%). All patients underwent 
TABLE 1. Patient characteristics

\begin{tabular}{|c|c|c|}
\hline Characteristic & No. of Patients & $\%$ \\
\hline Age at diagnosis (yrs) & 86 & \\
\hline$<40$ & 47 & 55 \\
\hline$\geq 40$ & 39 & 45 \\
\hline Sex & 82 & \\
\hline Male & 40 & 49 \\
\hline Female & 42 & 51 \\
\hline Side & 103 & \\
\hline $\mathrm{Lt}$ & 63 & 61 \\
\hline Rt & 40 & 39 \\
\hline Location & 106 & \\
\hline Frontal & 35 & 33 \\
\hline Parietal & 24 & 22 \\
\hline Temporal & 8 & 8 \\
\hline Other* & 39 & 37 \\
\hline EOR & 85 & \\
\hline GTR & 71 & 84 \\
\hline STR & 14 & 16 \\
\hline WHO grade & 109 & \\
\hline III & 68 & 62 \\
\hline$\|$ & 41 & 38 \\
\hline Postop radiation & 103 & \\
\hline Yes & 68 & 66 \\
\hline No & 35 & 34 \\
\hline Postop chemotherapy & 102 & \\
\hline Yes & 20 & 20 \\
\hline No & 82 & 80 \\
\hline
\end{tabular}

* Other tumor locations included frontoparietal, frontotemporal, parietooccipital, occipital.

surgical resection, with GTR achieved in $84 \%$ of cases. WHO Grade III tumors constituted the majority of hemispheric ependymomas (62\%). Radiation type and dose was available for 30/68 patients (focal only, $n=21$; focal with whole brain, $\mathrm{n}=5$; focal with craniospinal radiation, $\mathrm{n}=1$; whole brain only, $\mathrm{n}=3$ ). All patients received a radiation dose of 50 Gy or more.

There was a statistically significant correlation between age and higher tumor grade. Although WHO Grade III tumors were the most common type of tumor to occur in both younger and older age groups, patients 40 years and older were more likely to be diagnosed with a WHO Grade III tumor than younger patients were (OR 2.41,95\% CI 1.07-8.12; $\mathrm{p}=0.046)$. EOR was not associated with tumor grade $(\mathrm{p}=0.416)$. STR was not associated with postoperative chemotherapy $(\mathrm{p}=0.241)$ or postoperative radiation $(\mathrm{p}=0.632)$.

All patient information from our institutional case series is presented in Table 2. Common presenting symptoms were focal neurological deficit (5/8), headache (4/8), and seizure (2/8). Tumors were located in the frontal (4/8) and parietal (4/8) lobes. GTR was achieved in 4/8 patients.

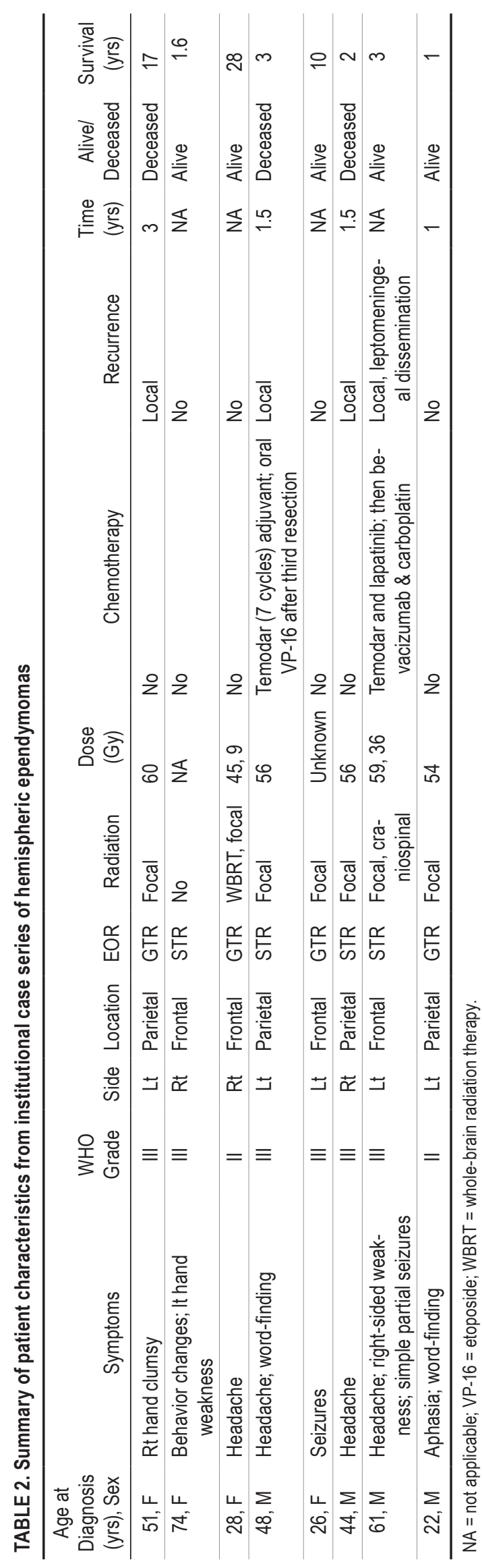


Postoperative radiation or chemotherapy, or both, were given to 7 and 2 patients, respectively.

\section{Kaplan-Meier Survival Analysis and Survival Rates for Study Population}

Kaplan-Meier survival curves were created for PFS (Fig. 1, left) and OS (Fig. 1, right). Three-, 5-, and 10-year PFS and OS data are presented in Table 3. Median PFS and OS were not achieved (recurrence 42/101; deaths 32/109); estimated median survival rates can be found in Table 3. The majority of patients had tumor recurrence within the first 3 years following tumor resection (43\%). Only $15 \%$ of tumors recurred between 3 and 10 years.

\section{Subgroup Kaplan-Meier Survival Analysis and Survival Rates Based on Prognostic Factors}

Log-rank testing for Kaplan-Meier survival analysis identified the EOR $(p<0.001)$ and tumor grade $(p<0.001)$ as significant predictors of PFS (Fig. 2A and C). Patients with STR and WHO Grade III ependymomas had worse PFS. EOR $(p<0.001)$ and tumor grade $(p=0.003)$ were also significant predictors of OS. STR and WHO Grade III ependymomas predicted worse OS, with STR predicting the worst survival outcome (Fig. 2B and D). Age, sex, tumor side, postoperative chemotherapy, and postoperative radiation were not prognostic for PFS and OS.

EOR and tumor grade subgroup PFS and OS rates are presented in the upper-right corner of the corresponding Kaplan-Meier curves (Fig. 2). Patients with STR or those with WHO Grade III tumors, or both, had significantly worse 3-, 5-, and 10-year PFS and OS. At 10 years, all patients with STR had tumor progression and were deceased.

In our institutional case series, 4 of 8 patients had tumor recurrence with a median PFS of 1.25 years. Three patients had local recurrence and 1 had leptomeningeal seeding. Three patients died, with all deaths resulting from tumor recurrence.

\section{Univariate and Multivariate Hazard Ratio Analysis of Prognostic Factors}

Hazard ratios (HRs) for prognostics factors were calculated using both univariate and multivariate Cox propor-
TABLE 3. Rates for PFS and OS

\begin{tabular}{lcc}
\hline \multicolumn{1}{c}{ Survival $(\mathrm{yrs})$} & $\%$ PFS $(\mathrm{n}=101)$ & $\%$ OS $(\mathrm{n}=109)$ \\
\hline 3 & 57 & 77 \\
\hline 5 & 51 & 71 \\
\hline 10 & 42 & 58 \\
\hline Estimated median* & $6.2 \mathrm{yrs}$ & $14.8 \mathrm{yrs}$ \\
\hline
\end{tabular}

* Median rates were not reached (total recurrences $=43 / 101$, total deaths $=$ $32 / 109)$.

tional hazard models. Summary of univariate and multivariate results are presented in Tables 4 and 5, respectively. Univariate analysis identified STR and WHO Grade III tumors as prognostic factors for worse PFS, with hazard ratios of 4.156 and 5.407, respectively. Univariate analysis for OS also identified EOR and tumor grade as prognostic factors. STR and WHO Grade III were predictive of worse OS with a hazard ratio of 4.964 and 3.771 , respectively. Neither postoperative radiation nor chemotherapy was prognostic for improved PFS or OS.

Multivariate analysis for prognostic factors was completed and included age, sex, tumor side, EOR, tumor grade, postoperative chemotherapy, and postoperative radiation. Only patients with complete clinical information were included in the analysis. A total of 77 patients with PFS and 79 patients with OS were included in the analysis. Both EOR and tumor grade had statistically significant HRs on multivariate analysis. Multivariate HRs are presented in Table 5.

\section{Discussion}

We present the largest clinical investigation of hemispheric ependymomas completed to date. Previous studies have been limited to case reports and case series. Because of the low incidence of these tumors in adults, pooling of institutional and reported data are a useful means to overcome small sample size. A total of 109 patients were included and analyzed for patient characteristics, survival, and prognostic factors. With approximately 350 adult supratentorial ependymomas diagnosed each year in the US,
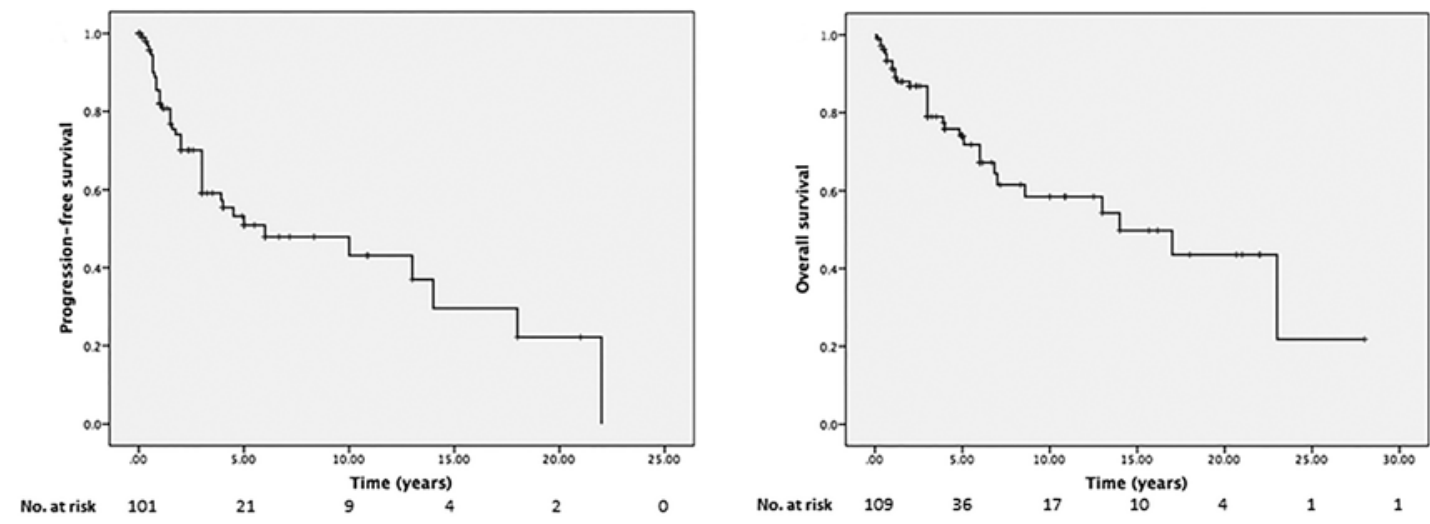

FIG. 1. Kaplan-Meier survival analysis for PFS (left) and OS (right) completed for the study population. 

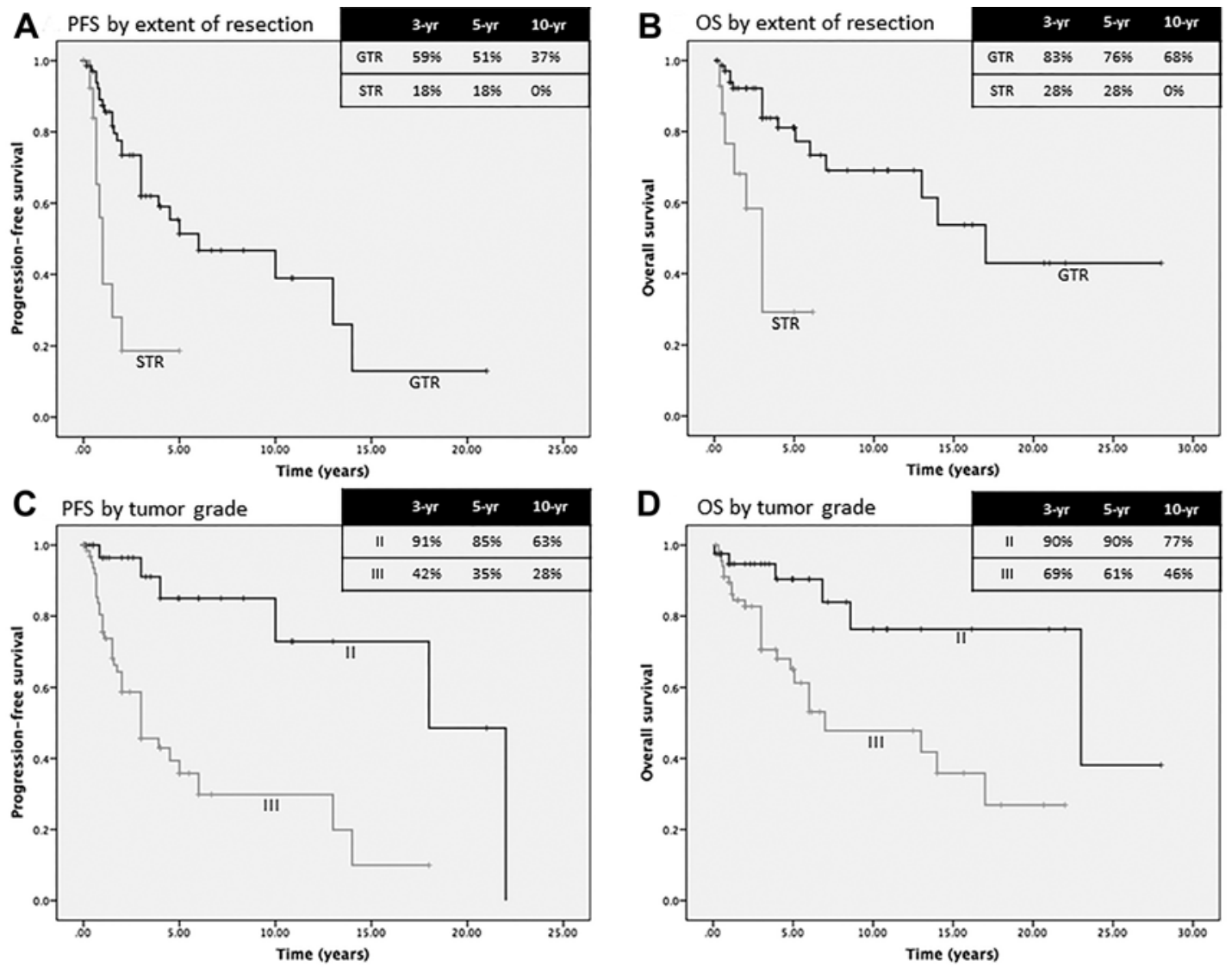

FIG. 2. Subgroup Kaplan-Meier survival analysis and survival rates were determined based on EOR and tumor grade prognostic factors. Kaplan-Meier curves are presented with corresponding survival rates in the upper right corner. A: PFS Kaplan-Meier curves for STR and GTR subgroups; there was a statistically significant difference for STR, which had a worse prognosis $(p<$ 0.001). B: OS Kaplan-Meier curves for STR and GTR subgroups; there was a statistically significant difference for STR, which had a worse prognosis $(p<0.001)$. C: PFS Kaplan-Meier curves for WHO Grade II and III tumors; a statistically significant difference was noted for Grade III tumors, which resulted in a worse PFS ( $<0.001)$. D: OS Kaplan-Meier curves for WHO Grade II and III tumors; a statistically significant difference was noted for Grade III tumors, which resulted in a worse PFS $(p=0.003)$.

our study captured a representative population of patients with hemispheric ependymomas. ${ }^{56}$

Adult males and females were equally affected. No age group was at increased risk for tumor occurrence. Hemispheric ependymomas were most common in the frontal lobes, but did not show a strong predilection for any location. GTR was achieved in the majority of cases (85\%). High rates of GTR may be attributed to the tendency of ependymomas to displace and compress, rather than infiltrate, surrounding brain parenchyma., 1,3,37 The tumor-brain interface is often well-demarcated both radiographically and intraoperatively. This is a unique feature of ependymomas compared with other gliomas. Surgical management of astrocytoma or oligodendroglioma results in STR in the majority of cases..$^{10,30}$ The more infiltrative nature of other gliomas, such as diffuse astrocytoma or malignant glioma, makes GTR more challenging. As our findings indicate that EOR is an important prognostic factor for OS and PFS, higher rates of GTR may contribute to longer survival times compared with low-grade and malignant gliomas. ${ }^{32}$

Anaplastic histology was found in $62 \%$ of hemispheric ependymomas, a larger percentage than previously reported for intracranial ependymomas (23\%-54\%).,14,21,38,46,47,53 Several series have also found a higher percentage of WHO Grade III tumors in hemispheric ependyomas. ${ }^{9,22,47,55}$ Guyotat and colleagues found that all 10 hemispheric ependymomas in their case series of 34 intracranial ependymomas had WHO Grade III pathology. ${ }^{9}$ Third and lateral ventricle tumors were split evenly between WHO Grade II and Grade III pathology. Another report found that $73 \%$ of hemispheric ependymomas (16/22 tumors) were WHO Grade III $(\mathrm{p}<0.05) .{ }^{22}$ Six $(75 \%)$ of the 8 patients in our institutional case series had WHO Grade III tumors. Our results provide evidence that hemispheric ependymomas have a greater likelihood of being WHO Grade III than infratentorial or spinal ependymomas in adults. While the explanation for this is unclear, it may be related to our finding that age was correlated with higher tumor grade. This is a feature common to astrocytomas and oligodendrogliomas, with incidence peaking at 35 to 44 years of age for low-grade tumors and 75 to 84 years of age for high-grade tumors. ${ }^{31}$ In our series, anaplastic histology 
TABLE 4. Univariate analysis of prognostic factors for PFS and $O S$

\begin{tabular}{|c|c|c|}
\hline Prognostic Factor* & PFS† & OS† \\
\hline Age at diagnosis (n) & 82 & 84 \\
\hline $\mathrm{HR}$ & 1.009 & 1.010 \\
\hline $95 \% \mathrm{Cl}$ & $0.987-1.031$ & $0.983-1.039$ \\
\hline p Value & 0.426 & 0.472 \\
\hline $\operatorname{Sex}(n)$ & 78 & 80 \\
\hline $\mathrm{HR}$ & 1.040 & 0.971 \\
\hline $95 \% \mathrm{Cl}$ & $0.529-2.045$ & $0.428-2.203$ \\
\hline p Value & 0.909 & 0.943 \\
\hline Tumor side (n) & 90 & 103 \\
\hline $\mathrm{HR}$ & 0.912 & 0.863 \\
\hline $95 \% \mathrm{Cl}$ & $0.475-1.750$ & $0.412-1.808$ \\
\hline$p$ Value & 0.782 & 0.696 \\
\hline $\mathrm{EOR}^{*}(\mathrm{n})$ & 81 & 83 \\
\hline $\mathrm{HR}$ & 4.156 & 4.964 \\
\hline $95 \% \mathrm{Cl}$ & $1.886-9.156$ & $1.918-12.848$ \\
\hline$p$ Value & 0.000 & 0.001 \\
\hline WHO grade $(n)$ & 96 & 109 \\
\hline $\mathrm{HR}$ & 5.407 & 3.771 \\
\hline $95 \% \mathrm{Cl}$ & $2.087-14.005$ & $1.439-9.881$ \\
\hline$p$ Value & 0.001 & 0.007 \\
\hline Postoperative radiation (n) & 93 & 101 \\
\hline $\mathrm{HR}$ & 1.006 & 0.992 \\
\hline $95 \% \mathrm{Cl}$ & $0.514-1.968$ & $0.446-2.206$ \\
\hline p Value & 0.986 & 0.984 \\
\hline Postoperative chemotherapy (n) & 92 & 100 \\
\hline $\mathrm{HR}$ & 1.543 & 1.020 \\
\hline $95 \% \mathrm{Cl}$ & $0.730-3.262$ & $0.409-2.546$ \\
\hline$p$ Value & 0.256 & 0.966 \\
\hline
\end{tabular}

* HRs were calculated such that values $>1$ reflect worse prognosis for STR and WHO Grade III tumors.

$\dagger$ Boldface values are statistically significant $(p<0.05)$, as determined by Cox proportional hazards model with 2-tailed tests for each prognostic factor.

was found in $80 \%$ of patients older than 40 years of age. The combination of hemispheric ependymomas having a greater incidence in adults and high-grade tumors correlating with age may account for our findings.

PFS and OS rates for hemispheric ependymomas did not differ substantially from previously reported rates for supratentorial ependymomas (Table 6). Five- and 10-year OS rates range from $35 \%$ to $79 \%$ and from $20 \%$ to $77 \%$, respectively. The wide range of reported values for PFS and OS in adults with supratentorial ependymomas likely results from small sample sizes, with most studies including less than 25 patients. Vera-Bolanos and colleagues examined the clinical course and PFS of adults with intracranial and spinal ependymomas. ${ }^{55} \mathrm{~A}$ total of 53 patients with supratentorial ependymomas were included for analysis. Kaplan-Meier survival analysis found similar PFS as that in the current study, with a median PFS of 4 years. Consistent with previous studies, supratentorial location
TABLE 5. Multivariate analysis of prognostic factors for PFS and $\mathrm{OS}^{*}$

\begin{tabular}{cll}
\hline Prognostic Factor & \multicolumn{1}{c}{ PFS } & OS \\
\hline EOR $(\mathrm{n})$ & 77 & 79 \\
\hline $\mathrm{HR}$ & 4.764 & 4.216 \\
\hline $95 \% \mathrm{Cl}$ & $1.952-11.626$ & $1.460-12.169$ \\
\hline $\mathrm{p} \mathrm{Value}$ & $\mathbf{0 . 0 0 1}$ & $\mathbf{0 . 0 0 8}$ \\
\hline WHO grade $(\mathrm{n})$ & 77 & 79 \\
\hline $\mathrm{HR}$ & 10.164 & 9.117 \\
\hline $95 \% \mathrm{Cl}$ & $2.216-46.612$ & $1.170-71.076$ \\
\hline $\mathrm{p} \mathrm{Value}$ & $\mathbf{0 . 0 0 3}$ & $\mathbf{0 . 0 3 5}$ \\
\hline
\end{tabular}

* Boldface values are statistically significant $(p<0.05)$, as determined by Cox proportional hazards model with 2-tailed tests for each prognostic factor. Age, sex, tumor side, extent of resection, tumor grade, postoperative radiation, and chemotherapy were included in the multivariate analysis. HRs were calculated such that values $>1$ reflect worse prognosis for STR and WHO Grade III tumors.

was a statistically significant prognostic factor for PFS. The majority of case series have found that supratentorial ependymomas carry a worse prognosis than infratentorial tumors do in adults. ${ }^{9,19,20,23,38,45,46,54}$

Our data support EOR and tumor grade as the most important prognostic factors for adult hemispheric ependymomas. An unanticipated finding was that sex, age, and postoperative radiation were not prognostic for PFS or OS. Female sex, ${ }^{20}$ younger age,,$^{21,38}$ and postoperative radiation ${ }^{20,46,51,54}$ have all been reported as prognostic for improved survival in intracranial ependymomas. Postoperative radiation has become commonplace in the management of anaplastic intracranial ependymomas..$^{20,46,48,54}$ However, Vera-Bolanos et al. and our study, the 2 largest series evaluating prognostic factors, did not find a benefit to postoperative radiation. Further clinical investigation will be needed to determine the efficacy of radiation treatment in hemispheric ependymomas.

STR was the strongest predictor of poor PFS and OS in our series. Ependymomas have long been considered a surgical disease best managed with safe maximal resection. Professional guidelines from the National Comprehensive Cancer Network emphasize the importance of complete resection (http://www.nccn.org/professionals/ physician_gls/f_guidelines.asp\#site). Re-resection may be appropriate in the setting of initial STR with radiographic evidence of residual tumor. For patients with residual tumor, only $28 \%$ survived 5 years and no patient survived 10 years. EOR has emerged as an essential prognostic factor for hemispheric low- and high-grade gliomas. ${ }^{10,16,43,50}$ Our study supports the view that, similar to other hemispheric gliomas, patients with hemispheric ependymomas benefit from safe maximal resection. Hemispheric ependymomas are intraaxial parenchymal tumors that warrant the same surgical management strategies as astrocytomas and oligodendrogliomas. Advanced surgical techniques, such as functional pathway mapping and intraoperative MRI, should be used to maximize tumor resection and prolong patient survival. ${ }^{12}$ 
TABLE 6. Previously reported PFS, OS, and prognostic factors for supratentorial ependymomas

\begin{tabular}{|c|c|c|c|c|c|c|c|}
\hline Authors \& Year & $\begin{array}{c}\text { No. of } \\
\text { Patients }\end{array}$ & Location & 5 -Yr PFS \% & $10-Y r$ PFS \% & $5-Y r$ OS \% & $10-Y r$ OS \% & Prognostic Factors for Worse OS \\
\hline Marks \& Adler, 1982 & 19 & Supratentorial & 16 & & 35 & & Supratentorial \\
\hline Vanuystel et al., 1992 & 40 & Supratentorial & 37 & 34 & 48 & 40 & WHO Grade III, STR, male, no radiation \\
\hline McLaughlin et al., 1998 & 10 & Supratentorial & & & & 20 & Supratentorial \\
\hline Schild et al., 1998 & 13 & Supratentorial & & & 62 & & Supratentorial, WHO Grade III \\
\hline Schwartz et al., 1999 & 23 & Supratentorial & 42 & 27 & 77 & 77 & WHO Grade III \\
\hline Guyotat et al., 2002 & 23 & Supratentorial & 28 & 23 & 43 & 25 & Supratentorial, WHO Grade III \\
\hline Reni et al., 2004 & 37 & Supratentorial & & & 70 & 31 & Supratentorial, age \\
\hline Kawabata et al., 2005 & 21 & Supratentorial & 46 & 39 & 63 & 46 & WHO Grade III, STR \\
\hline Metellus et al., 2007 & 46 & Supratentorial & 37 & 28 & 77 & 62 & STR, WHO Grade III, age, KPS score \\
\hline Metellus et al., 2010 & 22 & Supratentorial & 53 & 35 & 79 & 74 & Supratentorial, STR, KPS score \\
\hline Current study, 2015 & 111 & Hemispheric & 51 & 42 & 71 & 58 & WHO Grade III, STR \\
\hline
\end{tabular}

KPS = Karnofsky Performance Scale.

Previous reports conflict on the prognostic value of tumor grade in adult ependymomas., ${ }^{9,14,33,36}$ Our study provides evidence that WHO Grade III hemispheric ependymomas have a worse PFS and OS compared with WHO Grade II tumors in adults. With only $46 \%$ of patients with WHO Grade III tumors surviving to 10 years, compared with $77 \%$ of patients with WHO Grade II tumors, tumors with anaplastic histology are likely to demonstrate a more aggressive clinical course. The higher incidence of WHO Grade III pathology and associated poorer prognosis potentially contribute to the worse overall prognosis for hemispheric ependymomas compared with infratentorial ependymomas.

The limitations of our study result from the difficulty of investigating the clinical features and outcomes of a rare brain tumor. The inclusion of patients reported in the literature introduces selection bias and patient heterogeneity into the study population. To standardize the study population and avoid systematic error as much as is feasible, we included common categorical variables that were largely observer independent. Performance status and tumor dimensions were excluded to avoid measurement error. Patient characteristics, PFS, and OS were comparable to that reported in other clinical studies, reflective of a representative patient sample. The efficacy of specific postoperative radiation and chemotherapy regimens was not statistically analyzed due to sample size. Evaluation of each regimen with sufficient sample sizes would be needed to make definitive claims on treatment efficacy.

\section{Conclusions}

In summary, we analyzed 109 adults with supratentorial hemispheric ependymomas for survival and prognostic factors. WHO Grade III tumors constituted $62 \%$ hemispheric ependymomas, a higher percentage than either infratentorial or spinal ependymomas. Five- and 10-year OS rates were $71 \%$ and $58 \%$, respectively. EOR and tumor grade were identified as prognostic factors for both PFS and OS on multivariate analysis. Postoperative radiation was not found to be prognostic for PFS or OS. Our findings provide hitherto unknown clinical information that we hope will aid in the optimal evaluation and management of patients with hemispheric ependymomas.

\section{Acknowledgments}

We thank Dr. Sandra Camelo-Piragua for her generous contribution of the pathology images and recommendations on included pathology.

\section{References}

1. Berger MS, Prados M (eds): Textbook of Neuro-Oncology, ed 1. Philadelphia: Elsevier Saunders, 2005

2. Brandes AA, Cavallo G, Reni M, Tosoni A, Nicolardi L, Scopece L, et al: A multicenter retrospective study of chemotherapy for recurrent intracranial ependymal tumors in adults by the Gruppo Italiano Cooperativo di Neuro-Oncologia. Cancer 104:143-148, 2005

3. Centeno RS, Lee AA, Winter J, Barba D: Supratentorial ependymomas. Neuroimaging and clinicopathological correlation. J Neurosurg 64:209-215, 1986

4. Dahlback HS, Brandal P, Krossnes BK, Fric R, Meling TR, Meza-Zepeda LA, et al: Multiple chromosomal monosomies are characteristic of giant cell ependymoma. Hum Pathol 42:2042-2046, 2011

5. Davis MJ, Hasan F, Weinreb I, Wallace MC, Kiehl TR: Extraventricular anaplastic ependymoma with metastasis to scalp and neck. J Neurooncol 104:599-604, 2011

6. Ehtesham M, Kabos P, Yong WH, Schievink WI, Black KL, Yu JS: Development of an intracranial ependymoma at the site of a pre-existing cavernous malformation. Surg Neurol 60:80-83, 2003

7. Freyschlag CF, Tuettenberg J, Lohr F, Thomé C, Schmieder $\mathrm{K}$, Seiz M: Response to temozolomide in supratentorial multifocal recurrence of malignant ependymoma. Anticancer Res 31:1023-1025, 2011

8. Garrett PG, Simpson WJ: Ependymomas: results of radiation treatment. Int J Radiat Oncol Biol Phys 9:1121-1124, 1983

9. Guyotat J, Signorelli F, Desme S, Frappaz D, Madarassy G, Montange MF, et al: Intracranial ependymomas in adult patients: analyses of prognostic factors. J Neurooncol 60:255268,2002

10. Hervey-Jumper SL, Berger MS: Role of surgical resection in 
low- and high-grade gliomas. Curr Treat Options Neurol 16:284, 2014

11. Hiniker A, Lee HS, Chang S, Berger M, Perry A: Cortical ependymoma with unusual histologic features. Clin Neuropathol 32:318-323, 2013

12. Hollon T, Hervey-Jumper SL, Sagher O, Orringer DA: Advances in the surgical management of low-grade glioma. Semin Radiat Oncol 25:181-188, 2015

13. Iwamoto N, Murai Y, Yamamoto Y, Adachi K, Teramoto A: Supratentorial extraventricular anaplastic ependymoma in an adult with repeated intratumoral hemorrhage. Brain Tumor Pathol 31:138-143, 2014

14. Kawabata Y, Takahashi JA, Arakawa Y, Hashimoto N: Longterm outcome in patients harboring intracranial ependymoma. J Neurosurg 103:31-37, 2005

15. Kojima A, Yamaguchi N, Okui S, Kamiya M, Hirato J, Nakazato Y: Parenchymal anaplastic ependymoma with intratumoral hemorrhage: a case report. Brain Tumor Pathol 20:85-88, 2003

16. Lacroix M, Abi-Said D, Fourney DR, Gokaslan ZL, Shi W, DeMonte F, et al: A multivariate analysis of 416 patients with glioblastoma multiforme: prognosis, extent of resection, and survival. J Neurosurg 95:190-198, 2001

17. Liu Z, Li J, Liu Z, Wang Q, Famer P, Mehta A, et al: Supratentorial cortical ependymoma: case series and review of the literature. Neuropathology 34:243-252, 2014

18. Lombardi G, Pambuku A, Bellu L, Della Puppa A, Rumanò L, Gardiman MP, et al: Cisplatin and temozolomide combination in the treatment of supratentorial anaplastic ependymoma. Chemotherapy 59:176-180, 2013

19. Marks JE, Adler SJ: A comparative study of ependymomas by site of origin. Int J Radiat Oncol Biol Phys 8:37-43, 1982

20. McLaughlin MP, Marcus RB Jr, Buatti JM, McCollough WM, Mickle JP, Kedar A, et al: Ependymoma: results, prognostic factors and treatment recommendations. Int J Radiat Oncol Biol Phys 40:845-850, 1998

21. Metellus P, Barrie M, Figarella-Branger D, Chinot O, Giorgi $\mathrm{R}$, Gouvernet J, et al: Multicentric French study on adult intracranial ependymomas: prognostic factors analysis and therapeutic considerations from a cohort of 152 patients. Brain 130:1338-1349, 2007

22. Metellus P, Figarella-Branger D, Guyotat J, Barrie M, Giorgi R, Jouvet A, et al: Supratentorial ependymomas: prognostic factors and outcome analysis in a retrospective series of 46 adult patients. Cancer 113:175-185, 2008

23. Metellus P, Guyotat J, Chinot O, Durand A, Barrie M, Giorgi R, et al: Adult intracranial WHO grade II ependymomas: long-term outcome and prognostic factor analysis in a series of 114 patients. Neuro Oncol 12:976-984, 2010

24. Miyazawa T, Hirose T, Nakanishi K, Uozumi Y, Tsuzuki N, Shima K: Supratentorial ectopic cortical ependymoma occurring with intratumoral hemorrhage. Brain Tumor Pathol 24:35-40, 2007

25. Molina OM, Colina JL, Luzardo GD, Mendez OE, Cardozo D, Velasquez HS, et al: Extraventricular cerebral anaplastic ependymomas. Surg Neurol 51:630-635, 1999

26. Moritani S, Kushima R, Bamba M, Kobayashi TK, Oka H, Fujimoto M, et al: Highly anaplastic extraventricular ependymoma arising in an adult, mimicking metastatic adenocarcinoma with heavy stromal inflammation and emperiporesis. Pathol Int 53:539-546, 2003

27. Nakamizo S, Sasayama T, Kondoh T, Inoue S, Shiomi R, Tanaka H, et al: Supratentorial pure cortical ependymoma. J Clin Neurosci 19:1453-1455, 2012

28. Ng DW, King NK, Foo AS, Sitoh YY, Lee HY, Ng WH: Anaplastic supratentorial cortical ependymoma presenting as a butterfly lesion. Surg Neurol Int 3:107, 2012

29. Niazi TN, Jensen EM, Jensen RL: WHO Grade II and III su- pratentorial hemispheric ependymomas in adults: case series and review of treatment options. J Neurooncol 91:323-328, 2009

30. Orringer D, Lau D, Khatri S, Zamora-Berridi GJ, Zhang K, Wu C, et al: Extent of resection in patients with glioblastoma: limiting factors, perception of resectability, and effect on survival. J Neurosurg 117:851-859, 2012

31. Ostrom QT, Bauchet L, Davis FG, Deltour I, Fisher JL, Langer CE, et al: The epidemiology of glioma in adults: a "state of the science" review. Neuro Oncol 16:896-913, 2014

32. Ostrom QT, Gittleman H, Farah P, Ondracek A, Chen Y, Wolinsky Y, et al: CBTRUS statistical report: Primary brain and central nervous system tumors diagnosed in the United States in 2006-2010. Neuro Oncol 15 (Suppl 2):ii1-ii56, 2013

33. Oya N, Shibamoto Y, Nagata Y, Negoro Y, Hiraoka M: Postoperative radiotherapy for intracranial ependymoma: analysis of prognostic factors and patterns of failure. J Neurooncol 56:87-94, 2002

34. Palma L, Celli P, Cantore G: Supratentorial ependymomas of the first two decades of life. Long-term follow-up of 20 cases (including two subependymomas). Neurosurgery 32:169175,1993

35. Pang KY, Ho WW, Wong CK: Supratentorial extraventricular ependymoma: Literature review and case report. Ann Coll Surg HK 6: 22-24, 2002

36. Paulino AC, Wen BC, Buatti JM, Hussey DH, Zhen WK, Mayr NA, et al: Intracranial ependymomas: an analysis of prognostic factors and patterns of failure. Am J Clin Oncol 25:117-122, 2002

37. Reni M, Brandes AA: Current management and prognostic factors for adult ependymoma. Expert Rev Anticancer Ther 2:537-545, 2002

38. Reni M, Brandes AA, Vavassori V, Cavallo G, Casagrande F, Vastola F, et al: A multicenter study of the prognosis and treatment of adult brain ependymal tumors. Cancer 100:1221-1229, 2004

39. Rodríguez D, Cheung MC, Housri N, Quinones-Hinojosa A, Camphausen K, Koniaris LG: Outcomes of malignant CNS ependymomas: an examination of 2408 cases through the Surveillance, Epidemiology, and End Results (SEER) database (1973-2005). J Surg Res 156:340-351, 2009

40. Romero FR, Zanini MA, Ducati LG, Vital RB, de Lima Neto NM, Gabarra RC: Purely cortical anaplastic ependymoma. Case Rep Oncol Med 2012:541431, 2012

41. Roncaroli F, Consales A, Fioravanti A, Cenacchi G: Supratentorial cortical ependymoma: report of three cases. Neurosurgery 57:E192, 2005

42. Saito T, Oki S, Mikami T, Kawamoto Y, Yamaguchi S, Kuwamoto K, et al: [Supratentorial ectopic ependymoma: a case report.] No Shinkei Geka 27:1139-1144, 1999 (Jpn)

43. Sanai N, Polley MY, McDermott MW, Parsa AT, Berger MS: An extent of resection threshold for newly diagnosed glioblastomas. J Neurosurg 115:3-8, 2011

44. Sato Y, Ochiai H, Yamakawa Y, Nabeshima K, Asada Y, Hayashi T: Brain surface ependymoma. Neuropathology 20:315-318, 2000

45. Sayegh ET, Aranda D, Kim JM, Oh T, Parsa AT, Oh MC: Prognosis by tumor location in adults with intracranial ependymomas. J Clin Neurosci 21:2096-2101, 2014

46. Schild SE, Nisi K, Scheithauer BW, Wong WW, Lyons MK, Schomberg PJ, et al: The results of radiotherapy for ependymomas: the Mayo Clinic experience. Int J Radiat Oncol Biol Phys 42:953-958, 1998

47. Schwartz TH, Kim S, Glick RS, Bagiella E, Balmaceda C, Fetell MR, et al: Supratentorial ependymomas in adult patients. Neurosurgery 44:721-731, 1999

48. Shaw EG, Evans RG, Scheithauer BW, Ilstrup DM, Earle JD: Postoperative radiotherapy of intracranial ependymoma in 
pediatric and adult patients. Int J Radiat Oncol Biol Phys 13:1457-1462, 1987

49. Shuangshoti S, Rushing EJ, Mena H, Olsen C, Sandberg GD: Supratentorial extraventricular ependymal neoplasms: a clinicopathologic study of 32 patients. Cancer 103:2598-2605, 2005

50. Smith JS, Chang EF, Lamborn KR, Chang SM, Prados MD, Cha S, et al: Role of extent of resection in the long-term outcome of low-grade hemispheric gliomas. J Clin Oncol 26:1338-1345, 2008

51. Stüben G, Stuschke M, Kroll M, Havers W, Sack H: Postoperative radiotherapy of spinal and intracranial ependymomas: analysis of prognostic factors. Radiother Oncol 45:3-10, 1997

52. Takeshima H, Kawahara T, Uchida H, Hirano H, Nakazato Y, Kuratsu J: Brain surface ependymoma with repeated episodes of intratumoral hemorrhage-case report. Neurol Med Chir (Tokyo) 42:166-169, 2002

53. Van Gompel JJ, Koeller KK, Meyer FB, Marsh WR, Burger PC, Roncaroli F, et al: Cortical ependymoma: an unusual epileptogenic lesion. J Neurosurg 114:1187-1194, 2011

54. Vanuytsel LJ, Bessell EM, Ashley SE, Bloom HJ, Brada M: Intracranial ependymoma: long-term results of a policy of surgery and radiotherapy. Int J Radiat Oncol Biol Phys 23:313-319, 1992

55. Vera-Bolanos E, Aldape K, Yuan Y, Wu J, Wani K, NecesitoReyes MJ, et al: Clinical course and progression-free survival of adult intracranial and spinal ependymoma patients. Neuro Oncol 17:440-447, 2015
56. Villano JL, Parker CK, Dolecek TA: Descriptive epidemiology of ependymal tumours in the United States. Br J Cancer 108:2367-2371, 2013

57. Winn HR, Youmans JR: Youmans Neurological Surgery, ed 5. Philadelphia: Saunders, 2004, Vol 4

58. Youkilis AS, Park P, McKeever PE, Chandler WF: Parasagittal ependymoma resembling falcine meningioma. AJNR Am J Neuroradiol 22:1105-1108, 2001

\section{Disclosures}

The authors have no conflicts of interest to report pertaining to the materials or methods used in this study or the findings specified in this paper.

\section{Author Contributions}

Conception and design: Orringer, Junck. Acquisition of data: all authors. Analysis and interpretation of data: all authors. Drafting the article: Hollon, Lewis. Critically revising the article: all authors. Reviewed submitted version of manuscript: all authors. Approved the final version of the manuscript on behalf of all authors: Orringer. Statistical analysis: Nguyen. Study supervision: Orringer, Junck.

\section{Correspondence}

Daniel A. Orringer, Department of Neurosurgery, University of Michigan, 1500 E. Medical Center Dr., Rm. 3552 TC, Ann Arbor, MI 48109-5338. email: dorringe@ med.umich.edu. 